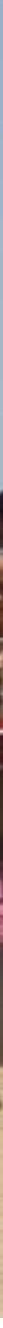

Baile de Folía en la Romería de San Benito (Cerro de Andévalo). Foto: Aniceto Delgado Méndez, IAPH 


\title{
Danzas rituales, capacidad adaptativa y vigencia de viejos usos culturales
}

\author{
Juan Agudo Torrico, Dpto. de \\ Antropologia Social y Cultural, \\ Universidad de Sevilla
}

Son doce las poblaciones onubenses que conservan danzas rituales, constituyendo uno de los conjuntos patrimoniales más ricos de Andalucía. De ellas, nueve (a las que habría que adscribir Villablanca por la ubicación del núcleo de población y características de su danza) pertenecen al Andévalo.

Desconocemos cuál es su origen, si bien se suele relacionar con tradiciones precristianas, ya sean danzas de exaltación guerrera o rituales encaminados a proteger a la comunidad. En la realidad histórica, debieron ser introducidas con el proceso de repoblación castellano-leonesa desarrollado entre los siglos XIII y XVI; aunque hasta bien entrado el s. XX apenas si tenemos constancia historiográfica de su existencia. Probablemente la condición popular que han tenido estas danzas y los danzantes que las ejecutaban ha hecho que su presencia no fuera considerada lo suficientemente importante como para ser reflejada en la documentación institucionalizada. El dato más antiguo con el que contamos hasta el presente se refiere a una desaparecida danza ritual ejecutada en el s. XVII en Villanueva de los Castillejos en honor de la Virgen del Rosario. Sin embargo, sí conocemos la historia de la última danza que se incorpora a esta tradición, reflejando la capacidad adaptativa y vigencia de estos viejos usos culturales: en Cabezas Rubias, en 1983 se crea la danza de San Sebastián, al tiempo que revitalizan los rituales patronales, se erige una ermita rural y se organiza ex novo una romería en su honor.

Acorde con la memoria colectiva conservada se sabe que los danzantes pertenecieron a los sectores sociales más humildes de las poblaciones. Su actuación era a la vez un acto ritual y festivo, por la estrecha vinculación mantenida hasta el presente entre danza, rituales religiosos, y festejos en los que intervienen; aunque como danzas rituales sólo actuarán en estos contextos festivo-ceremoniales, sin que se conciban los rituales sin su actuación, tampoco la danza se ejecuta fuera de unos rituales que justifican su origen y han dado sentido a su continuidad en el tiempo.

Ahora bien, el valor que actualmente se da a estas danzas y el sentimiento con el que se vivencia la participación entre los danzan- tes como un acto de devoción altruista no siempre fueron así. Si la danza contribuia a crear el tiempo de fiesta, el que no faltara era responsabilidad de los mayordomos, y a ellos correspondía organizarla, gratificar o agasajar a los danzantes por su intervención, y pagar a los tamborileros.

En el presente son las hermandades, creadas o reactivadas en la segunda mitad del siglo $X X$, las que organizan los rituales $y$ controlan las danzas. Las mayordomías han sido progresivamente desplazadas, aunque todavía mantienen un destacado protagonismo simbólico determinando incluso algunas secuencias en el desarrollo de la danza, como es la recogida y acompañamiento de los mayordomos; acto presente en prácticamente todos los rituales y que en ocasiones da lugar a significativas intervenciones de los danzantes en los prolegómenos de los propios rituales (San Bartolomé, Cabezas Rubias, El Cerro de Andévalo).

Las décadas de los años sesenta y setenta del siglo pasado supusieron un tiempo de inflexión y crisis en estos rituales. El despoblamiento y desestructuración del mundo rural afectó a los viejos valores comunitarios y sistemas festivo-ceremoniales, llegando incluso a desaparecer algunas de las viejas danzas, como la de San Antonio en Alosno, recuperada en 1997. Y en todos los casos fueron tiempos difíciles en los que, sin excepción, las danzas (percibidas por entonces como elementos accesorios de los propios rituales) corrieron riesgos de desaparición, con años en los que costaba trabajo reunir un mínimo número de danzantes para poder realizarlas.

Pero pese a las dificultades habidas algunos rasgos se han mantenido inalterables con el paso del tiempo. El primero es la condición de ser danzas exclusivamente varoniles. Son variadas las razones dadas para justificar este hecho (antiguas prohibiciones eclesiásticas que excluian a las mujeres, relación con costumbres guerreras u oficios varoniles, resistencia física para estar danzando el largo tiempo que duran los rituales, etc.), aunque la argumentación final dominante para mantener esta costumbre no es otra que la fuerza de una tradición que debe ser perpetuada por sí misma. 
En el transcurso del último tercio

del siglo XX, se irá produciendo la dignificación de la indumentaria, al tiempo que se reafirma su simbología ritual y las danzas dejan de ser meros componentes o acompañamientos festivos en procesiones y romerías

La relativa excepción a esta regla la encontramos en El Cerro de Andévalo, donde mayordomas y jamugueras comparten los bailes de la folía y fandangos con los danzantes; aunque nunca la danza ritual que sólo los varones ejecutan delante de la imagen.

Tampoco ha cambiado la composición impar de los grupos de danzantes. Denominados a sí mismos como "la danza" (confundiéndose los sujetos que los componen con la acción que realizan), están compuestos por un número variable de danzantes, entre un máximo de los 19 de San Juan en Alosno y los 7 de San Benito en El Cerro de Andévalo. De entre ellos, únicamente se singulariza al que va en cabeza. Va a ser quien marque el ritmo de los pasos y la secuencia de las mudanzas, determinando la mayor o menor vistosidad de la danza.

Los cambios más significativos en estas últimas décadas se relacionan con las variables de edad e indumentarias. La crisis a la que hemos aludido obligó a recurrir a niños para que las danzas no se perdieran. Cuando posteriormente, a partir de los años ochenta, se produzca la revitalización de las danzas al compás de su transformación en relevantes señas identitarias locales, varias poblaciones recuperan los grupos de mayores: Sanlúcar de Guadiana, El Almendro y Villanueva de los Castillejos. En estos casos, a los que hay que sumar otras poblaciones que crearon ex profeso grupos infantiles para garantizar el relevo generacional, se ha producido una significativa transformación de la estructura ritual: ambos grupos intervienen en los festejos, ya sea en el mismo dia y acontecimiento ritual, o distribuyéndose los tiempos rituales. Aunque también hay poblaciones que tienen a gala el que nunca se perdiera la tradición de la danza vieja, por lo que los mayores ni abandonaron ni cedieron su protagonismo ritual: San Bartolomé de la Torre.

Respecto a la indumentaria, en el pasado los danzantes, incluso diferenciándose entre ellos, vestían sencillos trajes campesinos, con alpargatas o zapatillas, pantalones oscuros de pana, fajas, y camisas blancas con cuello de tirilla. A lo sumo, unos mantoncillos sobre los hombros o bandas cruzadas por el pecho indicaban la transformación de estas vestimentas cotidianas en indumentarias rituales. En el transcurso del último tercio del siglo XX, se irá produciendo la dignificación de su indumentaria, al tiempo que se reafirma su simbología ritual y las danzas dejan de ser meros componentes o acompañamientos festivos en procesiones y romerías. Prácticamente todas las poblaciones "mejoran" los trajes de los danzantes, a la vez que acentúan las particularidades diferenciadoras entre pueblos, rituales y danzas. A partir de ahora, en varias poblaciones, los pantalones se acortan hasta media pierna, la pana es sustituida por terciopelo azul o negro, y ornamentan sus perniles con cascabeles, madroños o botones forrados; las piernas se cubren con medias de algodón caladas; anchas fajas ornamentales de vivos colores, algunas con laboriosos bordados, sustituyen a las de trabajo; las camisas blancas se ribetean de encajes finos en mangas, pecheras y cuellos; los chalecos, cuando se conservan, se hacen de telas multicolores o cuidadosamente bordadas (El Cerro de Andévalo, San Bartolomé de la Torre), con caireles o botones forrados; los antiguos pañuelos de trabajo que cubrian la cabeza o anudaban a la frente se sustituyen

\section{DANZAS RITUALES ONUBENSES}

\begin{tabular}{|c|c|c|c|c|c|c|c|c|c|}
\hline Localidad & $\begin{array}{l}\text { Advocación } \\
\text { titular }\end{array}$ & $\begin{array}{l}\text { Condición de } \\
\text { la imagen }\end{array}$ & $\begin{array}{l}\text { Denominación } \\
\text { de la danza }\end{array}$ & Tipo de ritual & $\begin{array}{l}\text { Número de } \\
\text { danzantes }\end{array}$ & $\begin{array}{l}\text { Elementos } \\
\text { que portan }\end{array}$ & $\begin{array}{l}\text { Denominación } \\
\text { de los danzantes }\end{array}$ & $\begin{array}{l}\text { Denominación } \\
\text { primer } \\
\text { danzante }\end{array}$ & $\begin{array}{l}\text { Denominación } \\
\text { último } \\
\text { danzante }\end{array}$ \\
\hline Alosno & $\begin{array}{l}\text { S. Juan } \\
\text { Bautista }\end{array}$ & Patronal & Cascabeleros & Procesión urbana & 19 & Palillos & Cascabeleros & Cabeza & \\
\hline Alosno & $\begin{array}{l}\text { S. Antonio de } \\
\text { Padua }\end{array}$ & Grupal & $\begin{array}{l}\text { Danza de } \\
\text { espadas }\end{array}$ & Procesión urbana & 15 & Espadas & Danzantes & & Rabeaor \\
\hline $\begin{array}{l}\text { Cabezas } \\
\text { Rubias }\end{array}$ & S. Sebastián & Patronal & $\begin{array}{l}\text { Danza de San } \\
\text { Sebastián }\end{array}$ & $\begin{array}{l}\text { Procesión urbana / } \\
\text { Romería }\end{array}$ & 9 & Espadas & Lanzaores & $\begin{array}{l}\text { Guia / } \\
\text { Cabeza }\end{array}$ & Rabeaor \\
\hline $\begin{array}{l}\text { El Almendro } \\
\text { / Villanueva } \\
\text { de los } \\
\text { Castillejos }\end{array}$ & $\begin{array}{l}\text { V. de Piedras } \\
\text { Albas }\end{array}$ & Patronal & $\begin{array}{l}\text { Danza de los } \\
\text { Cirochos / } \\
\text { sirochos }\end{array}$ & Romeria & 15 & Palillos & Cirochos & Guión & \\
\hline $\begin{array}{l}\text { El Cerro de } \\
\text { Andévalo }\end{array}$ & $\begin{array}{l}\text { S. Benito } \\
\text { Abad }\end{array}$ & Patronal & $\begin{array}{l}\text { Danza de las } \\
\text { lanzas }\end{array}$ & $\begin{array}{l}\text { Romeria / } \\
\text { Procesión urbana }\end{array}$ & 7 & Lanzas & Lanzaores & Cabeza & Rabeón \\
\hline $\begin{array}{l}\text { Puebla de } \\
\text { Guzmán }\end{array}$ & V. de la Peña & Patronal & $\begin{array}{l}\text { Danza de } \\
\text { espadas }\end{array}$ & Romería & 11 & Espadas & Danzantes & Capitán & Rabeón \\
\hline $\begin{array}{l}\text { San } \\
\text { Bartolomé de } \\
\text { la Torre }\end{array}$ & S. Bartolomé & Patronal & $\begin{array}{l}\text { Danza de } \\
\text { espadas }\end{array}$ & Procesión urbana & 9 & Espadas & Danzantes & Cabeza & $\begin{array}{l}\text { Rabeaor / } \\
\text { rabero }\end{array}$ \\
\hline $\begin{array}{l}\text { Sanlúcar de } \\
\text { Guadiana }\end{array}$ & $\begin{array}{l}\text { V. de la } \\
\text { Rábida }\end{array}$ & Patronal & $\begin{array}{l}\text { Danza Virgen de } \\
\text { la Rábida }\end{array}$ & Procesión urbana & 11 & $\begin{array}{l}\text { Palillos/ } \\
\text { Arquillos }\end{array}$ & Danzantes & La Cruz & \\
\hline $\begin{array}{l}\text { Villanueva de } \\
\text { las Cruces }\end{array}$ & S. Sebastián & Patronal & $\begin{array}{l}\text { Danza de los } \\
\text { garrotes }\end{array}$ & Procesión urbana & 11 & Garrotes & Danzantes & Cabeza & Rabero \\
\hline
\end{tabular}



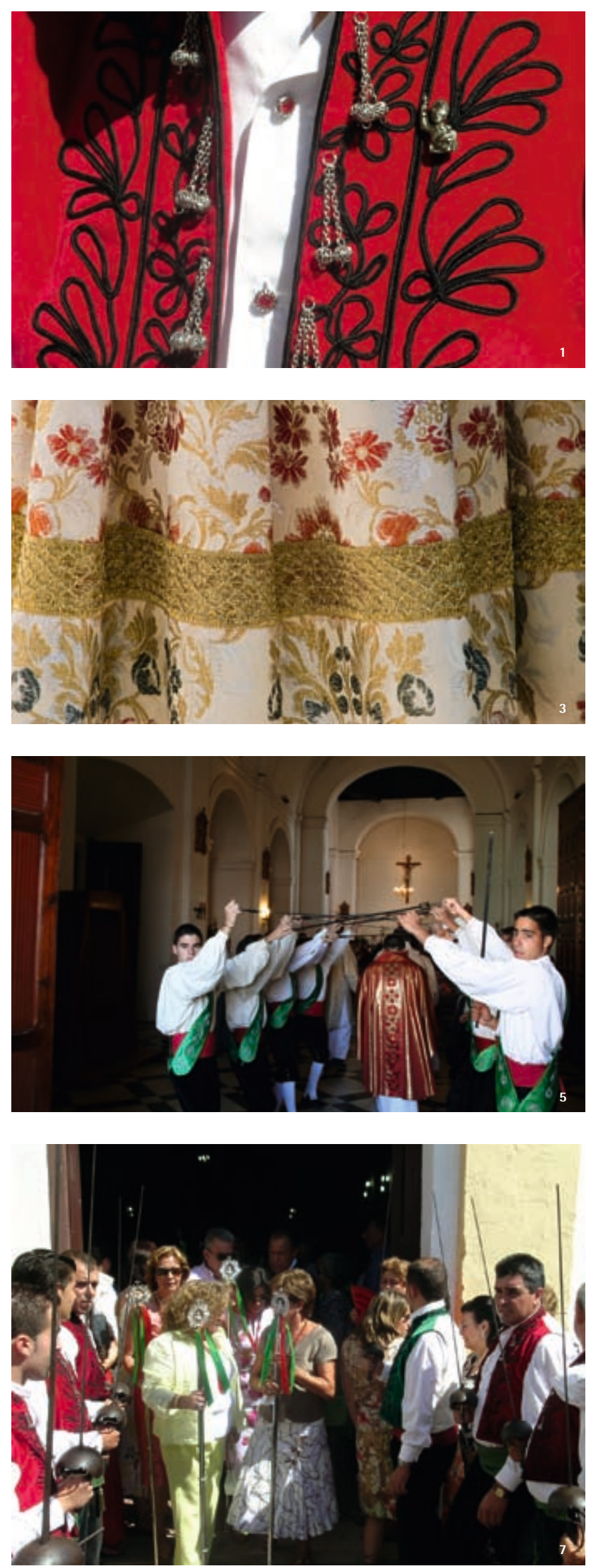

1. Chaleco danzante de San Bartolomé de la Torre. Foto: Juan Agudo Torrico

3. Detalle traje jamuguera (Cerro de Andévalo).

Foto: Aniceto Delgado Méndez, IAPH

5. Danzantes de Cabezas Rubias.

Foto: Juan Agudo Torrico

7. Salida de mayordomos de la fiesta de San Bartolomé

(San Bartolomé de la Torre). Foto: Juan Agudo Torrico
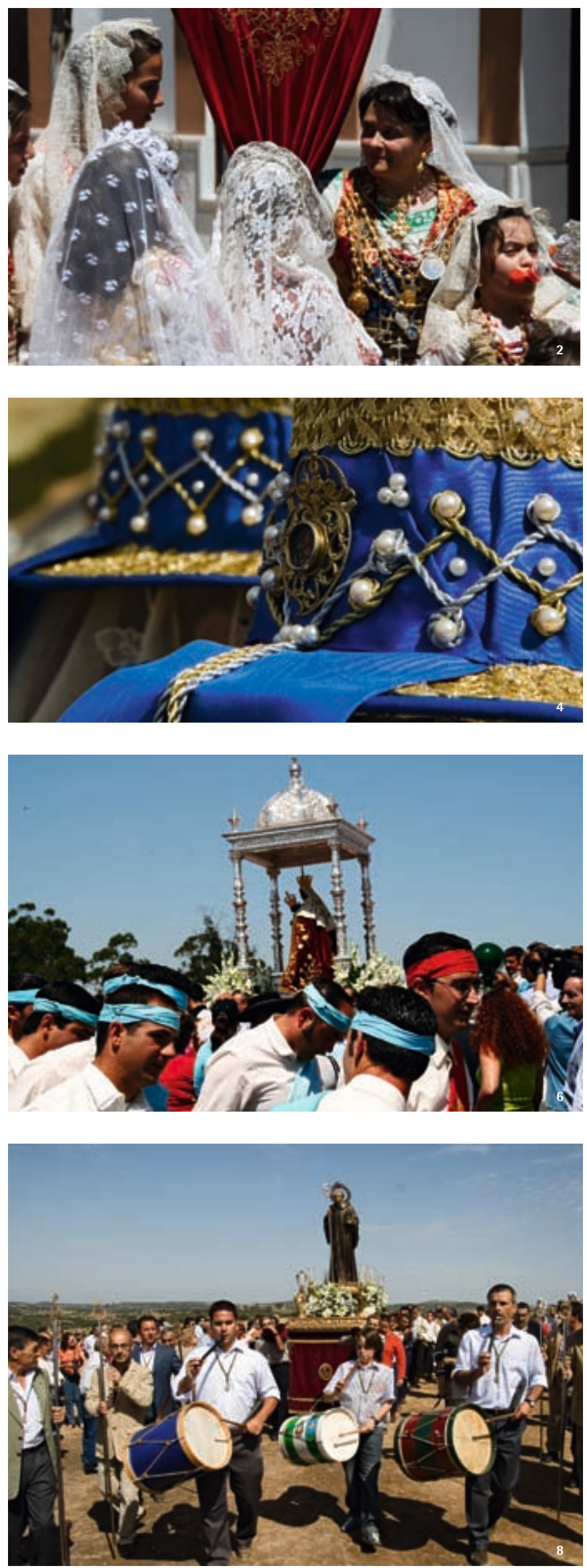

2. Traje de Jueves de Comadre (Procesión de San Juan, Alosno).

Foto: Aniceto Delgado Méndez, IAPH

4. Detalle sombrero jamuguera (Cerro de Andévalo).

Foto: Aniceto Delgado Méndez, IAPH

6. Danzantes de Puebla de Guzmán en la Romería de la Virgen de la Peña. Foto: Aniceto Delgado Méndez, IAPH

8. Tamborileros en la Romería de San Benito (El Cerro de Andévalo) Foto:Aniceto Delgado Méndez, IAPH 



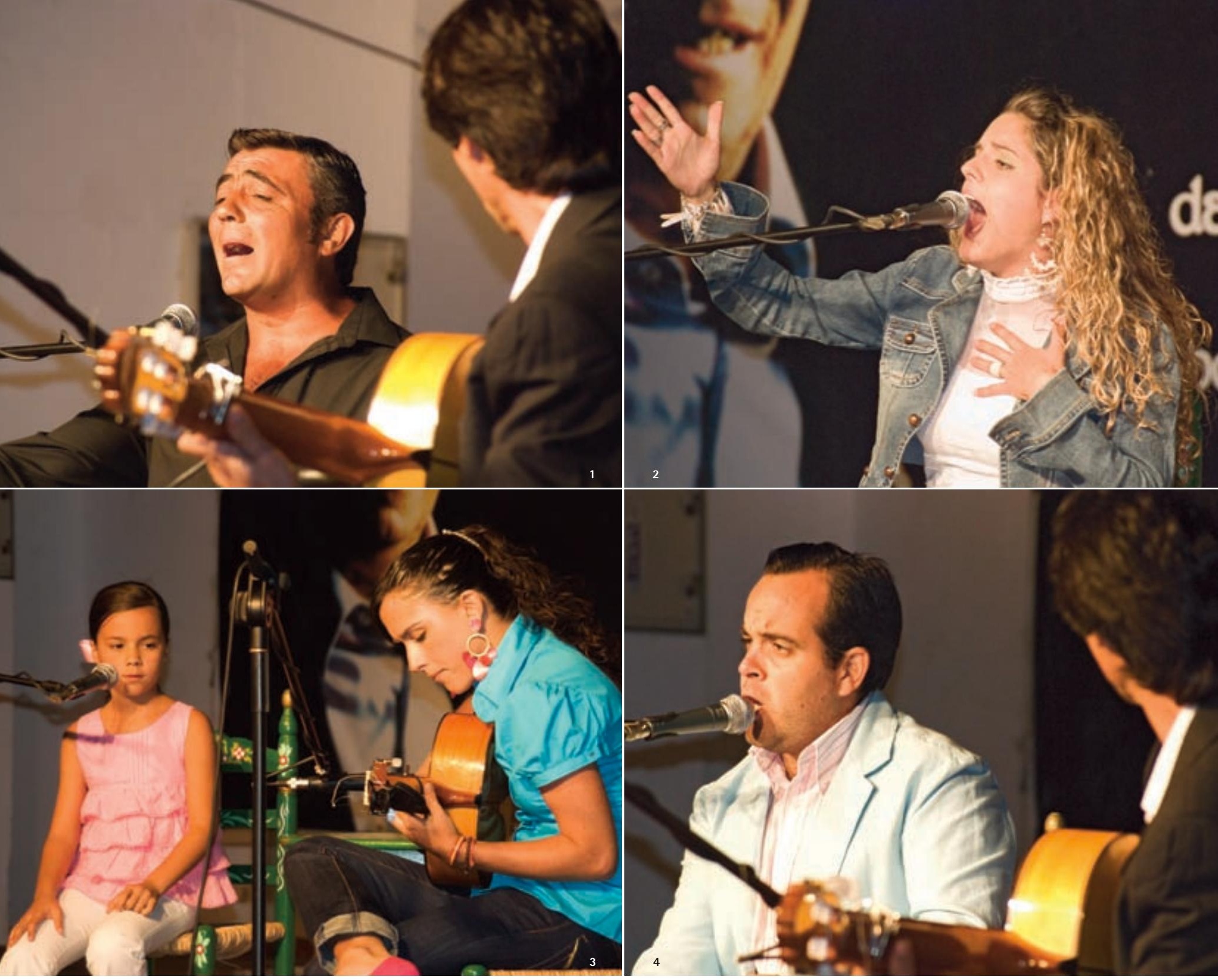

Certamen Nacional de Fandango "Paco Toronjo" (Alosno). Fotos: Aniceto Delgado Méndez, IAPH

\section{El fandango en Alosno}

Habrá pocos pueblos en la geografía española tan ligados a un tipo determinado de música como Alosno lo ha estado desde siempre al fandango. En innumerables ocasiones he oido fuera de nuestros limites la expresión: -"¿eres de Alosno?, jentonces cantarás fandangos!", como si el mero hecho de nacer en esta localidad otorgara la facultad de dominar esta modalidad musical.

$Y$ bien es verdad que aunque este sea un tipo de cante común por otras localidades de la provincia onubense, en Alosno se ha vivido desde siempre de una manera especial el mundo del fandango. Es rara la casa en la que aún no se conserve como oro en paño una colección manuscrita con cientos de letras, recopiladas a través de años por alguno de los componentes de la familia, normalmente una mujer, y en las que se recoge en cada uno de sus cinco versos todo sobre lo humano y lo divino, sobre el amor y el desamor, sobre la mina y el campo, sobre los animales y las plantas; en definitiva, la vida escrita en fandangos.

Sin embargo, en los tiempos de bonanza que corren en los últimos años para el fandango con la realización de numerosos concursos y certámenes dedicados especificamente a este cante, pocos concursantes proceden desde la conocida localidad andevaleña. $Y$ no es una novedad. Desde que allá a mediados del siglo pasado los Hermanos Toronjo dieran a conocer a través de grabaciones y actuaciones en directo, no sólo el fandango, sino gran parte del patrimonio musical alosnero fuera de sus fronteras, se pueden contar con los dedos de una mano el número de cantaores originarios de Alosno que se han prodigado por los difíciles caminos artísticos.

Y es que para el alosnero el fandango va más allá del mundo del espectáculo. La mayoria de los aficionados de Alosno no han pisado en vida un escenario, ni saben de micrófonos, de focos o de públicos. Sin embargo son capaces de poner el vello de punta a cualquiera cuando una noche de Cruz de Mayo, una Vispera de San Juan o en alguna de las ocasiones que el extenso calendario festivo alosnero lo permite, lanzan su quejío al aire, desgranando con sus letras y su particular estilo lo más sentido y profundo, como una viva y real expresión de pureza de los cantes de este pueblo, y con unos matices musicales que sólo por estas tierras se le saben imprimir al fandango.

\section{Ramón Díaz Pérez}

Técnico de Cultura del Ayuntamiento de Alosno 